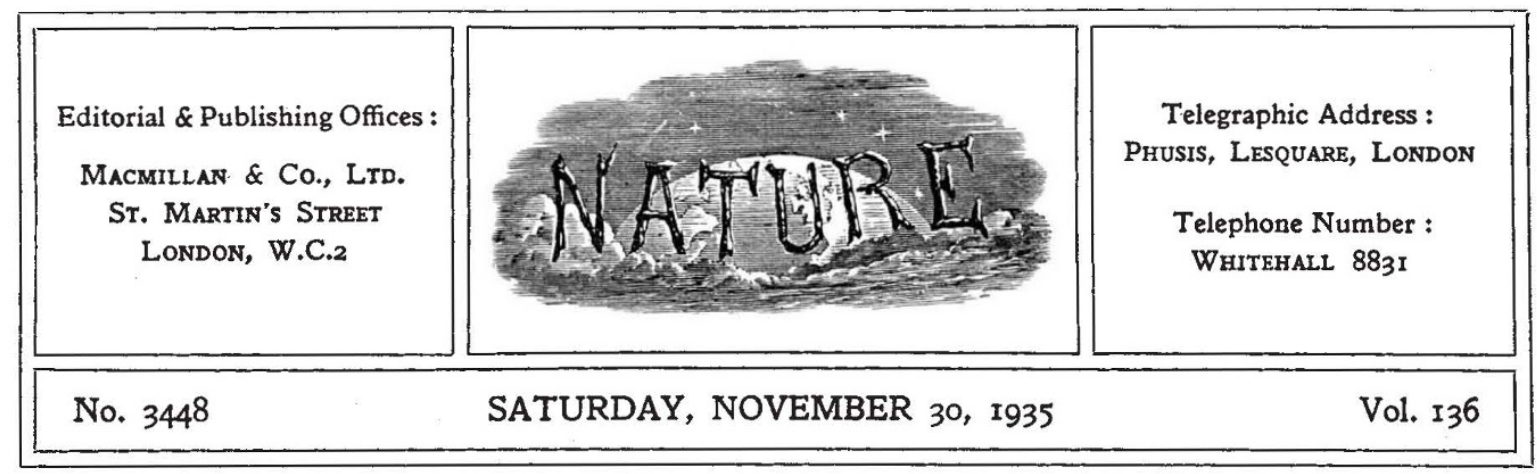

\title{
Education and Leisure in Progressive Life
}

$\mathrm{T}^{\mathrm{H}}$ HE extent of unemployment in the world to-day in itself has forced attention on the problem of leisure. Plans have already been proposed for the wider distribution of leisure as a contribution towards the reduction of unemploy. ment by raising the age of entry to industry at one end and lowering the age of exit at the other. Similarly, the reduction of working hours has been advocated as a means of distributing leisure and employment more equably.

Behind such proposals lies the fundamental belief that the increased powers of production which the advance of mechanical and physical science has placed within man's power, if rightly used, make possible a higher standard of living for all and also the attainment of that standard through less physical effort and with consequent greater leisure than ever before. Already this belief is challenging economic and political systems or dogma which prevent the realisation either of that higher standard of living or that fairer distribution. There is a widespread readiness to try new methods if the old prove inadequate.

The very linking of the problem of leisure with that of unemployment in such ways as these has, however, proved an obstacle to clear thinking on the fundamental issues with which the coming of leisure confronts us. Only slowly are we coming to see that education must be a preparation for leisure as much as for work.

Work and leisure cannot well be separated; one is complementary to the other. Life must be viewed as a whole, and, whether from the educational point of view or the wider social point of view, a society which does not provide the training or the facilities for the adequate enjoyment of leisure is in as dangerous a condition as a society in which training and opportunities for earning a livelihood are defective. The view of education as a preparation not merely for work but also for life, the conception that the provision of adequate facilities for recreation and the right use of leisure is a prime function of the State, are so revolutionary as to involve a radical change in our views on education and other questions.

The situation calls for much creative and fundamental thought, and it was with this conviction that in 1934 the New Education Fellowship com. menced a comprehensive inquiry into the subject. The outcome of the first part of this inquiry is embodied in a report which has recently been issued under the title "The Coming of Leisure"*. This report outlines the problem as it exists in England to-day, and shows the directions in which solutions are being sought. It formed one basis of the discussions at a conference held at the University of St. Andrews on August 13-22.

The report naturally starts with the problem which leisure presents to education in its narrower sense. If education, whether at school or in adolescence or in adult life, is to be a preparation not merely for work but also for life, the fundamental policies in our system of national education require drastic modification. The belief that we have merely to teach a child a certain number of subjects with some relevance to the way in which he is to earn his living, and which will provide him with a modicum of knowledge and give him the facility for acquiring more, is hopelessly inadequate if we are to educate for leisure.

If therefore education is to help youth to master the means of making life worth while a new method of approach may be required if not an entirely new technique, and a complete change in

* The Coming of Leisure: the Problem in England. Edited by E. B. Castle, A. K. C. Ottaway and W. T. R. Rawson. Pp. 78. (London: New Education Fellowship, 1935.) 28. 6d. 
the attitude of both teachers and administrators. Notably is this true in the reorganised elementary school if the purpose of the Hadow report is to be realised, and unhappily all too rarely is there betrayed in discussions on the raising of the school leaving age any realisation of the possibilities of wider experiment and adventure in education which are bound up in the reorganisation outlined in that report.

The difficult problems which leisure and education present in adolescence are largely the result of defective education at an earlier stage. Even in adolescence, the question of idle hours due to unemployment can assume serious dimensions. Such idle hours must not be termed leisure. Neither education for leisure nor any other kind of education is possible for human beings living a precarious and hand-to-mouth existence. The essential basis for the education of the adult, whether regularly employed or not, is freedom from the grosser evils of poverty, helplessness and the sense of not being wanted. It is only in an atmosphere of freedom from these evils that the expression of personality is possible and the creative instinct finds full play.

This, in fact, is the centre of the problem-the securing of full play for human personality and the creative instinct within the ranks of an organised society. It involves, of course, much more than education. It involves the evolution of sociology into an organised science, as distinct from a mere body of organised knowledge, as well as the working out of ways and means by which the enormous increase in the productive powers placed in man's hands may be utilised to secure a wider and more equable distribution of leisure for all, together with the higher standard of living which is possible with the wise use of such powers.

These are tasks demanding no small measure of scientific investigation and creative thought as well as wise statesmanship, and it is only when they have been accomplished that the educationist can enter on his full opportunity. In the meantime he has much preparatory work to do. Apart altogether from his influence in the training of the right type of leader, his influence may easily be decisive in the formation of a society and a public mind which is capable of supporting and following great leadership. The statesman, it must be remembered, too often has to content himself with what he believes it to be possible to get accepted, not with what he believes to be the most altruistic and noblest solution of a problem.
Even in this work of developing a society with a capacity to accept change and advance to a finer social order, the educationist has much to do. What may be termed the educational climate of the country has completely changed. The extensive growth of social amenities, the cheap production of books, magazines and newspapers, the influence of the cinema, the wireless and gramophone have diminished the demand for formal education. The educational process has become more and more one of unconscious absorption and less and less the deliberate satisfaction of a conscious need.

This change has several consequences. It enforces close consideration of possibilities which both the cinema and broadcasting offer for cultural purposes, and the development of a new and appropriate technique both for schools and for adult education. It demands also the development of a new technique of art education which shall contribute to the enrichment of leisure hours, and encourage the expression of creative instincts and personality whether in speech or drama, in reading or in writing. Again, the advance of science and the gradual replacement of physical labour by mechanical power have enhanced the need for physical education, so that physical recreation represents one of the major problems in the right use of leisure. Scarcely anywhere is there more need of wise and skilful guidance to secure the full value from existing opportunities and to guard against unbalanced or untoward effects whether in games, in handicraft or in gardening and like activities.

Much the same applies to the opportunities for what may be described as social adventures pro. vided by young people's clubs and societies whether of the indoor type or for camping and rambling or the like. Wise guidance is again needed if gifts for leadership are to be encouraged and developed and not repressed, and the full value of such activities realised.

Yet another consequence is even more fundamental. Progress may well depend finally on whether we are able to liberate the world from what Prof. William McClelland has rightly termed the degrading exploitation of mass suggestion. All the evidence suggests that we are in the midst of a new renaissance through which humanity is struggling to rise to a higher level of culture. We have to prepare youth for a world where everything is in a state of flux, and the fundamental need is to train up a strong flexible creative generation with 
the spirit of adventure of the pioneer on the intellectual side. To do this, education must be continuously directed towards preparing youth to think for itself. Freedom of thought is an essential preliminary alike to the creative thought which is our supreme need or to that intelligent thought on vital issues in social and international relationship in which statesmanship can function.

More and more it becomes apparent that what is needed is not merely the capacity to deal with and evaluate facts, but also the capacity to deal with contingent truth. Far too little training is given in arriving at opinions, weighing evidence, sifting motives, discounting prejudices and resisting suggestions. The very advance of science itself depends upon the development of such capacity. Prof. Julian Huxley has recently indicated how sociology can only develop into a true science as it formulates its methods for dealing with multiple effect and multiple causation.
The coming of leisure thus sets before us not indeed the problem of education for leisure but of re-examining and re-orientating our whole system of education for life. Very largely indeed the survival of civilisation depends upon our capacity to plan and put into force an educational policy, wisely co-ordinated over the whole field, so as to produce citizens capable not merely of efficient workmanship but also physically and mentally equipped to enjoy the full resources of life at our disposal. These are the conditions in which independent and creative thought is possible and in which leadership will flourish. Our task, as Whitehead reminds us, is not the production of great leaders. A great society will always put up the great men for the occasion. It is the task of establishing a great society in which adventurous and creative thought and living flourish, and to that task the whole range of problems involved in the increase of leisure summon us anew.

\section{Agricultural Production and National Nutrition}

\section{The Agricultural Dilemma:}

a Report of an Enquiry organised by Viscount Astor and Mr. B. Seebohm Rowntree. Pp. xiii + 101. (London: P. S. King and Son, Ltd., 1935.) $2 s$. $6 d$. net.

IN the volume before us Lord Astor and Mr. B. Seebohm Rowntree present the results of an inquiry organised by them into the possibilities of increasing the agricultural population of Great Britain. The 'dilemma' which the authors postulate is the difficulty of reconciling increasing employment in the production of foodstuffs at home with increasing technical efficiency, falling population, the nationalistic policies of other countries, and Great Britain's relationship-in peace and in war-with the Empire overseas, and with friendly neutral countries. The conclusion is reached that the present conditions of overproduction and unremunerative prices will prove in some degree a persistent rather than a transient phenomena: that imports of vegetables, poultry, fruit, etc., have already been reduced to the limit that is desirable: that any drastic reduction of our imports of such special foodstuffs as wheat, beef, mutton and bacon (which alone could allow of a specific increase in domestic production) would seriously aggravate the economic difficulties of the world, would entail a further loss of export trade and imperil the solidarity of the British Empire and our good relations with neutral foodproducing countries.

If it were not for the element of truth in some of these arguments, our agricultural policy would be easy-no need for quotas, trade agreements or marketing boards. What a delightful life for the Minister of Agriculture. As it is, however, he has to build a structure within the main girders of a national policy, utilising as best he can those girders which are already in position, adjusting others, or persuading his colleagues that the main building will be the more secure if a few of his brand new ones take the place of theirs.

What this book in fact tells us is that we had better give up hopes of any material increase in agricultural production. Whereas the inquiry specifically set out to determine the possibilities of expanding land settlement, the conclusions must relate to increased production, whether from new or existing producers. Is it unfair to presume that the same conclusions would have been reached by the same authors four years ago? We think not, for the arguments applied then as now. Yet they have been entirely falsified. Production has increased, agriculture has received considerable benefit, and neither the cost of living nor our export trade has suffered. 